University of Nebraska - Lincoln

DigitalCommons@University of Nebraska - Lincoln

$1-2019$

\title{
Capital and Punishment: Resource Scarcity Increases Endorsement of the Death Penalty
}

Keelah E. G. Williams

Ashley M. Votruba

Steven L. Neuberg

Michael J. Saks

Follow this and additional works at: https://digitalcommons.unl.edu/psychfacpub

Part of the Law and Psychology Commons, Legal Studies Commons, Psychology Commons, and the Social Control, Law, Crime, and Deviance Commons

This Article is brought to you for free and open access by the Psychology, Department of at DigitalCommons@University of Nebraska - Lincoln. It has been accepted for inclusion in Faculty Publications, Department of Psychology by an authorized administrator of DigitalCommons@University of Nebraska - Lincoln. 
Published in Evolution and Human Behavior 40:1 (January 2019), pp. 65-73; doi: 10.1016/j.evolhumbehav .2018.08.002

Copyright (C) 2018 Elsevier Inc. Used by permission.

Submitted January 23, 2018; revised August 7, 2018; accepted August 8, 2018; published online August 10, 2018.

Supplemental appendixes follow the references.

\title{
Capital and Punishment: Resource Scarcity Increases Endorsement of the Death Penalty
}

\author{
Keelah E. G. Williams, ${ }^{1}$ Ashley M. Votruba, ${ }^{2}$ Steven L. Neuberg, ${ }^{3}$ \\ and Michael J. Saks ${ }^{3,4}$
}

1. Hamilton College, Department of Psychology, Clinton, New York, USA

2. University of Nebraska-Lincoln, Department of Psychology, Lincoln, Nebraska, USA

3. Arizona State University, Department of Psychology, Tempe, Arizona, USA

4. Arizona State University, Sandra Day O'Connor College of Law, Phoenix, Arizona, USA

Corresponding author - Keelah E. G. Williams, Taylor Science Center, Hamilton College, 198 College Hill Road, Clinton, NY 13323, USA, email kewillia@hamilton.edu

\begin{abstract}
Faced with punishing severe offenders, why do some prefer imprisonment whereas others impose death? Previous research exploring death penalty attitudes has primarily focused on individual and cultural factors. Adopting a functional perspective, we propose that environmental features may also shape our punishment strategies. Individuals are attuned to the availability of resources within their environments. Due to heightened concerns with the costliness of repeated offending, we hypothesize that individuals tend toward elimination-focused punishments during times of perceived scarcity. Using global and United States data sets (studies 1 and 2), we find that indicators of resource scarcity predict the presence of capital punishment. In two experiments (studies 3 and 4), we find that activating concerns about scarcity causes people to increase their endorsement for capital punishment, and this effect is statistically mediated by a reduced willingness to risk repeated offenses. Perceived resource scarcity shapes our punishment preferences, with important policy implications.
\end{abstract}

Keywords: death penalty, scarcity, resource availability, punishment 


\section{Introduction}

Throughout history and across societies, severe transgressors have often been punished with death. Researchers studying contemporary hunter-gatherer societies have consistently found a custom of killing group members for severe offenses, including malicious sorcery, murder, theft, cheating, and betraying the group to outsiders (Boehm, 2012; Otterbein, 1986). Despite strong historical roots, the use of capital punishment is now politically controversial in much of the world. One hundred forty nations have abolished capital punishment (Amnesty International, 2017), yet the death penalty is still employed in many countries, including in 31 of the 50 states within the United States (Death Penalty Information Center, 2017).

\subsection{Proximate and ultimate approaches to understanding death penalty attitudes}

To explain divergent attitudes toward capital punishment, researchers have primarily examined proximate explanations. For example, some researchers find that support for the death penalty hinges on political ideology, with conservatism significantly predicting favorability toward the death penalty (e.g., Sarat, 2001). Related constructs, such as rightwing authoritarianism and individualist values, are also positively correlated with endorsement of the death penalty (Soss, Langbein, \& Metelko, 2003). At the nation level, capital punishment attitudes have been examined in relation to political stability (Miethe, Lu, \& Deibert, 2005), tolerance for deviant behavior (Gelfand et al., 2011), fear of crime (Liang, Lu, Miethe, \& Zhang, 2005), and social freedom (Neapolitan, 2001). However, little research has empirically examined capital punishment attitudes using an evolutionary lens. Exploring more ultimate explanations may therefore complement and deepen our understanding of why and under what circumstances people endorse the death penalty.

From an evolutionary perspective, there is ample evidence suggesting that evolved psychological mechanisms can have a robust influence on attitudes and preferences in a wide range of domains (e.g., Griskevicius, Delton, Robertson, \& Tybur, 2011; Hill, Rodeheffer, Durante, Griskevicius, \& White, 2012; Neuberg \& Schaller, 2016; White, Kenrick, Neel, \& Neuberg, 2013). Importantly, this literature demonstrates that our psychology, preferences, and attitudes are flexible in response to features of our environment, allowing for the adoption of ecologically functional strategies and behavior. Here, we adopt such a functional perspective, proposing that our punishment preferences should also be attuned to the environment-specifically, the perceived availability of resources.

\subsection{Psychological sensitivity to resource availability}

Our human ancestors faced fluctuations in prosperity and resource availability (Chakravarthy \& Booth, 2004; Griskevicius et al., 2013). Those better able to manage scarcity - by noticing its impending approach, and possessing better strategies for managing resources during difficult times-were more likely to survive and reproduce, leaving descendants with similar inclinations (White et al., 2013a). These evolved cognitive, affective, and behavioral strategies are likely to reside in the contemporary mind, becoming active in the presence of cues to scarcity (Griskevicius et al., 2011). 
Indeed, perceptions of resource scarcity influence a range of behaviors. For example, Griskevicius et al. (2013) found that experimentally manipulating perceived resource scarcity affected individuals' financial decision-making. In a series of studies, the researchers demonstrated that cues to economic recession (as compared to a control condition) led participants with low socioeconomic status backgrounds to increase their temporal discounting and preference for risky rewards. Research has also discovered a robust relationship between resource availability and reproductive timing, with resource scarcity at both the individual and nation level associated with earlier reproduction (e.g., Griskevicius et al., 2011). Lee and Zietsch (2011) found that priming resource scarcity in the lab shifted women's mate preferences, such that scarcity led women to favor traits indicating parental quality (e.g., "commitment" and "nurturing") rather than traits indicating genetic quality (e.g., "intelligence" and "muscularity"). Beyond these effects, perceptions of scarcity have also influenced food choice (Laran \& Salerno, 2013), categorization of racially ambiguous faces (Rodeheffer, Hill, \& Lord, 2012), moral behavior (Sharma, Mazar, Alter, \& Ariely, 2014), and attitudes toward economic redistribution (White et al., 2013a).

The logic underlying each of the findings above draws from the same premise: the availability of resources in one's environment affects the costs and benefits of adopting particular strategies. Inclinations and behaviors that enhance fitness in times of abundance may be maladaptive in times of scarcity, and vice versa. Our psychology has therefore evolved to flexibly - and functionally - respond to cues of resource availability.

\subsection{Resource scarcity and attitudes toward the death penalty}

Here, we propose that preferences for certain punishment strategies-specifically, capital punishment-also reflect sensitivity to resource availability. Punishing those who threaten group functioning is critical to successful human interdependence and cooperation (Boyd \& Richerson, 2006; Neuberg \& Cottrell, 2008). However, monitoring and punishing deviance is energetically costly. Resources spent monitoring and punishing transgressors within the group necessarily reduce the resources that can be spent on alternative tasks (e.g., acquiring food, shelter, and mates; protecting the group from outside threats). In addition, rehabilitating serious transgressors comes at some risk of failure.

On the other hand, the loss of a potentially useful group member through exile or death also carries costs - especially ancestrally, when humans lived in small, highly interdependent groups. This suggests that evaluating the opportunity costs associated with keeping severe transgressors in the group is inherently influenced by the severity of the threat posed by the transgressor; elimination-focused punishments should be reserved for wrongdoers who pose the most serious of threats. Supporting this notion is work by Boehm (2012), indicating that in forager groups, elimination-focused punishments are utilized when there is group agreement that certain individuals must be purged from the group, lest the survival of the entire group is threatened (see also Otterbein, 1986). Thus, when determining punishment of serious offenders, group members must weigh the relative costs and benefits of eliminating the threat against rehabilitating the transgressor.

This process reflects a functional error management system (Haselton \& Nettle, 2006; Nesse, 2005), in which determinations are likely to favor the least costly error. In the costbenefit analysis at hand, two possible errors can be made: individuals might (1) remove an 
offender who can be successfully reintegrated and offer valuable future contributions to the group, or (2) keep an offender within the group whose rehabilitation is unsuccessful and who imposes future costs on the group. We suggest that the availability of resources in one's environment affects the weighting of possible errors associated with expunging serious transgressors from the group. That is, which of these two errors is likely to be costlier depends in part on whether resources are abundant or scarce.

When resources are abundant, investing in the rehabilitation and reintegration of transgressors may prevent the loss of a potentially valuable group member at a relatively manageable cost to the group. Conversely, resource scarcity places the group in a precarious position, and the potential costs of keeping serious criminal offenders within the group may be prohibitively large. Given a bias toward making the less costly of possible errors (Haselton \& Nettle, 2006; Nesse, 2005), people may favor harsher, elimination-focused punishments when resources are scarce. Consequently, we hypothesized that perceptions of resource scarcity increase favorability toward capital punishment.

We note here the underlying assumption of our approach: whatever the relative costs of keeping severe transgressors in the group versus permanent removal of these individuals, these costs are likely to be greater when resources are scarce as compared to when resources are abundant. Our purpose here is not to directly test the assumption that the cost of transgression is especially high under times of scarcity, but to explore its implications in the context of modern-day attitudes toward the death penalty. If, however, we are incorrect in our underlying assumption, the predicted effects should not manifest.

To test our general hypothesis, we adopted two complementary strategies. First, using archival data, we examined whether a real-world relationship exists between resource availability and death penalty usage (Studies $1 \& 2$ ). Second, we examined the causal connection between resources and death penalty beliefs at the individual level by experimentally manipulating perceived resource availability and measuring beliefs about the death penalty and our putative mediator (Studies $3 \& 4$ ).

\section{Study 1}

Study 1 investigated the relationship between resource scarcity and death penalty laws at the nation level. As proxy for a country's level of resource availability, we obtained global data on human development in the 131 countries for which these measures were available. We also collected information about death penalty laws in each of these countries, creating a binary code indicating whether each country maintains capital punishment as a matter of law. We predicted that countries with lower human development would be more likely to maintain capital punishment than countries with higher human development.

\subsection{Materials and methods}

We first obtained global data on human development to use as our proxy for resource scarcity. Human development data were taken from the Inequality-Adjusted Human Development Index (IHDI) (2011). In evaluating and selecting our measure of resource scarcity, we considered a number of factors. First, it was necessary that the measure provide an accurate representation of resource harshness for the country as a whole. Thus, Gross 
Domestic Product (GDP) was inappropriate, as it would depict countries with large-but highly concentrated - wealth as resource abundant when a substantial portion of the population lives in resource scarce conditions (e.g., India).

Second, we sought a measure that would capture a holistic account of resource deprivation, to better approximate the multidimensionality of environmental harshness in a global setting. The IHDI is a nation-level measure of human development adjusted for inequality in a society and is compiled by the United Nations Development Programme. Three dimensions of "development" are captured by the IHDI: the extent to which residents of the country live long healthy lives (i.e., life expectancy); the extent to which residents experience a decent standard of living (i.e., personal income); and the extent to which residents are educated (i.e., years of schooling). Each of these dimensions is directly relevant for gauging economic resources: (1) socioeconomic factors are robustly linked to mortality (e.g., Stringhini et al., 2017); (2) personal income offers a direct measure of financial resources; and (3) years of education is robustly linked to lifetime earning (e.g., Oreopoulos \& Petronijevic, 2013). IHDI scores were obtained from the 131 countries for which this measure was available. We note that, unlike GDP, the IHDI is independent of population size. However, countries with larger population sizes generally experience more crime (e.g., Nolan, 2004), which may affect attitudes toward the death penalty. Therefore, we gathered information about the population size of each country to include as a potential covariate in our analyses. This information was obtained from the CIA World Factbook (2011).

Finally, we gathered information about death penalty laws in each country from Amnesty International (2012). We then created a binary code indicating whether each country maintains the death penalty as a matter of law. When determining whether a country maintains the death penalty, we coded each country as a single unit. Thus, if one region of a nation maintains the death penalty while others do not (as in the United States) that country was coded as having the death penalty.

\subsection{Focal results}

To test our hypothesis that countries with lower human development would be more likely to maintain the death penalty, we conducted a series of logistic regressions. As predicted, countries with lower IHDI scores - indicating lower levels of income and developmentwere significantly more likely to have the death penalty ( $\beta=-5.76$, Nagelkere $R^{2}$ (overall model) $=0.30, p<.001$ ). See Table 1 . Given that countries with larger populations likely have increased crime rates, we tested whether these findings held after controlling for population size by running a logistic regression with population size and human development as predictors. They did: although population size significantly predicted death penalty laws $(p=.01)$, human development remained a significant predictor of countries maintaining death penalty laws $\left(\beta=-6.03\right.$, Nagelkerke $R^{2}$ (overall model) $=0.38, p<.001$ ). See Table 2. 
Table 1. Study 1. Summary of Regression Analysis for IHDI Predicting Whether a Country Maintains Death Penalty Laws $(\mathrm{N}=131)$

\begin{tabular}{lcc}
\hline Variable & $\beta(p)$ & $S E \beta$ \\
\hline IHDI & $-5.76(<.001)$ & 1.15 \\
$R^{2}$ & & .30 \\
\hline
\end{tabular}

Table 2. Study 1. Summary of Regression Analysis for Population and IHDI Predicting Whether a Country Maintains Death Penalty Laws $(\mathrm{N}=131)$

\begin{tabular}{lcc}
\hline Variable & $\beta(p)$ & $S E \beta$ \\
\hline Population & $.01(.01)$ & .004 \\
IHDI & $-6.03(<.001)$ & 1.21 \\
$R^{2}$ & & .38 \\
\hline
\end{tabular}

\subsection{Additional analyses}

As discussed above, one advantage of the IHDI as a proxy measure for resource scarcity is that it provides a more accurate depiction of a country's deprivation by adjusting for inequality. One possibility, however, is that inequality itself might drive capital punishment-for example, by increasing homicide rates (Daly, 2016). For exploratory purposes, we therefore obtained measures of income equality (Gini coefficients) in all countries for which these data were available (CIA World Factbook, 2012) to test whether inequality, per se, also predicts presence of the death penalty.

As with our analyses using the IHDI, we first conducted a logistic regression with income inequality as the sole predictor of presence of the death penalty; inequality did not predict presence of death penalty laws in this model $(\beta=0.03, p=.13)$. A second model containing both inequality and population size as predictors also indicated no relationship between inequality and presence of the death penalty $(\beta=0.032, p=.152)$; population size remained a significant predictor of countries maintaining death penalty laws $(p=.005)$.

\subsection{Conclusions}

The first study provides preliminary evidence of a relationship between real-world resource scarcity and use of the death penalty. In addition, this relationship appears to be driven by the overall extent of deprivation in a country, rather than its distribution. However, a number of potential confounds exist, including the various cultural differences present across countries. Of course, such cultural confounds do not necessarily constitute alternative explanations. Rather, they may merely be more proximate mechanisms through which ecological factors such as resource scarcity have their effects. Nonetheless, Study 2 explored whether these patterns would emerge within a more culturally homogenous context by examining the relationship between resource availability and death penalty laws at the state level within the United States. 


\section{Study 2}

In the United States, individual state legislation determines whether the death penalty is available as a possible punishment. As proxy for a state's level of resource availability, we obtained state per capita income data for each of the 50 states. We also collected information about death penalty laws in each of these states, again employing a binary code indicating whether the state maintains capital punishment as a matter of law. We predicted that states with lower per capita income would be more likely to maintain capital punishment than states with higher per capita income.

\subsection{Measures}

Although state-level variability in income inequality exists, this variability is far less pronounced between states in the United States than between countries around the globe (CIA World Factbook, 2017). Therefore, as compared to our country-level investigation in Study 1 , we did not have similar concerns about within-state inequality distorting our data in Study 2. Thus, we selected state per capita income as a direct measure of resource availability. State per capita data for each of the 50 states was gathered from the United States Department of Commerce (2011). To maintain consistency with our broader conceptualization of resource deprivation, we also gathered data on state life expectancy (a component of IHDI in Study 1). These data were collected from the Measure of America (2014).

In anticipating alternative explanations for our findings, we collected several measures to include as covariates. First, state population size data were collected from the United States Census Bureau (2012). Second, state murder rate data were collected from the Death Penalty Information Center (2012). Finally, a measure of state political ideology was obtained from a Gallup State Ideology Survey (2012).

Following our procedure in Study 1, we gathered information about death penalty laws in each state (Death Penalty Information Center, 2012) and created a binary code indicating whether each state maintains the death penalty as a matter of law.

\subsection{Results}

To test our hypothesis - that states with lower per capita income and lower life expectancy would be more likely to maintain the death penalty - we conducted a series of logistic regressions. First, we ran logistic regressions using only our measure of resource deprivation as a predictor. As predicted, we found that states with lower per capita income were more likely to have the death penalty $\left(\beta=-1.51\right.$, Nagelkerke $R^{2}$ (overall model) $=0.20, p=.01$ ). Also as predicted, states with lower life expectancy were more likely to have the death penalty $\left(\beta=-0.67\right.$, Nagelkerke $R^{2}$ (overall model) $=0.23, p=.01$ ).

We then examined whether these effects would persist when state population size, murder rate, and political ideology were included in three separate regression models containing state per capita income. Results, including standardized beta coefficients and indicators of effect size, are summarized in Table 3. As predicted, state per capita income remained a significant predictor of death penalty laws after controlling for population size and murder rate in separate logistic regression analyses (both $p s \leq .03$ ). Further, neither population size nor murder rate were significant predictors of death penalty usage in these models (both 
$p s>$.12). In the model controlling for political ideology, states with lower per capita income remained marginally more likely to have the death penalty $(p=.098)$. Consistent with previous research, politically conservative states trended toward having the death penalty, but the effect was nonsignificant $(p=.12)$ in this model.

Table 3. Study 2. Summary of Regression Analyses (3 Separate Analyses) for State Per Capita Predicting Whether a State Maintains Death Penalty Laws $(\mathrm{N}=50)$

\begin{tabular}{|c|c|c|c|c|c|c|}
\hline \multirow[b]{2}{*}{ Variable } & \multicolumn{2}{|c|}{ Model 1} & \multicolumn{2}{|c|}{ Model 2} & \multicolumn{2}{|c|}{ Model 3} \\
\hline & $\beta(p)$ & $S E \beta$ & $\beta(p)$ & $S E \beta$ & $\beta(p)$ & $S E \beta$ \\
\hline Per Capita Income & $-1.59(0.008)$ & .60 & $-1.34(.03)$ & .60 & $-1.11(.10)$ & .67 \\
\hline Population & $.07(.25)$ & .06 & & & & \\
\hline Murder Rate & & & $.29(.12)$ & .19 & & \\
\hline Political Ideology & & & & & $.09(.12)$ & .06 \\
\hline$R^{2}$ & & .24 & & .26 & & .26 \\
\hline
\end{tabular}

Finally, we examined whether the effect of life expectancy would persist in three separate logistic regression models also containing either population size, murder rate, or political ideology. Again, life expectancy remained a significant or marginally significant predictor of death penalty laws in each model (all $p s \leq .08$ ); see Table 4. Population size, murder rate, and political ideology did not significantly predict death penalty laws in their respective models (all $p \mathrm{~s}>.18$ ).

Table 4. Study 2. Summary of Regression Analyses (3 Separate Analyses) for Life Expectancy Predicting Whether a State Maintains Death Penalty Laws $(\mathrm{N}=50)$

\begin{tabular}{|c|c|c|c|c|c|c|}
\hline \multirow[b]{2}{*}{ Variable } & \multicolumn{2}{|c|}{ Model 1} & \multicolumn{2}{|c|}{ Model 2} & \multicolumn{2}{|c|}{ Model 3} \\
\hline & $\beta(p)$ & $S E \beta$ & $\beta(p)$ & $S E \beta$ & $\beta(p)$ & $S E \beta$ \\
\hline Life Expectancy & $-.71(.009)$ & .27 & $-.58(.054)$ & .30 & $-.51(.08)$ & .29 \\
\hline Population & $.06(.22)$ & .05 & & & & \\
\hline Murder Rate & & & $.11(.59)$ & .21 & & \\
\hline Political Ideology & & & & & $.08(.18)$ & .06 \\
\hline$R^{2}$ & & .27 & & .24 & & .27 \\
\hline
\end{tabular}

\subsection{Conclusions}

Study 2 provides further supporting evidence that indicators of resource scarcity predict the presence of death penalty laws. Within the United States, states with lower per capita incomes and lower life expectancies are more likely to have capital punishment. These effects were observed despite inherently limited statistical power (50 states) and persisted after controlling for state population size, murder rate, and political ideology.

\section{Study 3}

Studies 1 and 2 provide initial evidence supporting a relationship between resource availability and use of the death penalty; however, the correlational nature of archival data precludes causal interpretation of these results. Additionally, Studies 1 and 2 are focused on 
whether resource availability is related to the maintenance of death penalty laws and do not directly assess individual psychology. Thus, in Study 3, we experimentally manipulated perceived resource availability to test whether resource scarcity causally shifts individuals' endorsement of the death penalty. We also explored whether our predicted effects would hold after controlling for participants' political ideology (the dominant extant explanation for death penalty attitudes) and socioeconomic status (an indicator of chronic resource availability). Given that threats to resource availability affect individuals across SES groups, we expected to see effects of the resource scarcity manipulation in both highand low-SES individuals.

\subsection{Materials and methods}

\subsubsection{Participants}

One hundred twenty-eight participants (64 women; Mage $=39.78$ ) were recruited in 2013 through Amazon's Mechanical Turk for a "Social Beliefs Survey." We aimed to recruit at least 50 participants per condition. In selecting our sample size, we examined previous studies employing similar resource availability manipulations (Griskevicius et al., 2013; Rodeheffer et al., 2012). However, we were mindful that death penalty attitudes tend to be strongly held and difficult to influence; thus, we anticipated a small effect size. Participants received $\$ 0.50$ compensation for completing the study.

\subsubsection{Procedure}

Each participant read a description of the study and provided informed consent before beginning the experiment. Participants were then instructed to carefully examine a series of photographs and accompanying text. Participants were randomly assigned to view one of two stories. Participants in the resource scarcity condition viewed photographs suggesting current economic hardship. Accompanying text indicated a continuing stagnation of the economy, with high unemployment, economic collapse, and frequent home foreclosures. The photos and text suggested that these current trends are likely to continue in the future. Participants in the resource abundance condition viewed photographs suggesting economic prosperity. Accompanying text indicated that the current economy is in an upswing, with high job growth, rising stock prices, higher pay, and many new home purchases. The photos and text also suggested that the current economic situation would continue to improve in the future. We note that Studies $3 \& 4$ were conducted in the years following the Great Recession-a time when the United States economic condition was somewhat ambiguous, and either of the induction scenarios would have been plausible to the average person. These manipulations have been successfully employed in past research examining the effects of resource scarcity on psychological processes (e.g., Rodeheffer et al., 2012; White et al., 2013a).

Immediately after viewing the photos and text, participants completed a self-report measure assessing death penalty attitudes. For exploratory purposes, participants also completed the Moral Foundations Questionnaire (Graham, Haidt, \& Nosek, 2008). Finally, 
participants responded to a number of demographic items assessing gender, socioeconomic status, and political ideology. Participants were then fully debriefed and thanked for their time.

\subsubsection{Death penalty attitudes measure}

Participants responded to three items assessing endorsement of the death penalty: "I think the death penalty is necessary," "The death penalty should be used more often than it is," and "The length of time between sentencing someone to death and actually executing them should be shorter than it currently is." Items were adapted from previous research examining death penalty attitudes (O'Neil, Patry, \& Penrod, 2004). Responses were reported on a 9-point scale ranging from 1 (strongly disagree) to 9 (strongly agree). A scale composite of these items was created $(\alpha=.87)$, which comprised our focal dependent variable.

\subsubsection{Socioeconomic status measure}

Participants reported their subjective socioeconomic status (SES) by responding to the item, "How would you describe your family's social-economic class, in terms of household income?" on a scale ranging from 1 ("Poor") to 5 ("Upper class").

\subsubsection{Political ideology measure}

Participants provided a self-reported assessment of their political ideology on a single item ranging from -50 ("Very Liberal") to +50 ("Very Conservative").

\subsubsection{Focal results}

We predicted that individuals in the resource scarcity condition would exhibit greater endorsement of the death penalty than those in the resource abundance condition. To test our prediction, we regressed the death penalty endorsement composite onto the dummycoded resource availability manipulation. A marginally significant effect of resource availability emerged, such that participants in the resource scarcity condition reported greater endorsement of the death penalty $\left(M_{\text {predicted }}=5.83, S E_{\text {predicted }}=.44\right)$ than participants in the resource abundance condition $\left(M_{\text {predicted }}=5.07, S E_{\text {predicted }}=.31\right)(\beta=.16, p=.08) .{ }^{1}$

We next explored whether our effects held after controlling for participants' political ideology and socioeconomic status. To examine whether resource availability influenced attitudes toward the death penalty above and beyond the effects of participants' socioeconomic status and political ideology, we regressed participants' reported endorsement of the death penalty onto socioeconomic status, political ideology, and resource condition, as well as all interaction terms in a single regression model. Results, as shown in Table 5, indicated a significant main effect of participant socioeconomic status, such that individuals with lower socioeconomic status reported greater endorsement of the death penalty than individuals with higher socioeconomic status $(\beta=-.25, p=.03)$. A main effect of political ideology also emerged, such that conservative participants reported greater endorsement of the death penalty than liberal participants $(\beta=.33, p=.01)$. However, despite these findings, the marginally significant main effect of resource availability on endorsement of the death penalty persisted and approached statistical significance $(\beta=.16, p=.07)$. None of the interaction terms were significant (all $p s>.17$ ). 
Table 5. Study 3. Summary of Regression Analysis for Variables Predicting Participants' Endorsement of the Death Penalty $(\mathrm{N}=120)$

\begin{tabular}{lcc}
\hline Variable & $\beta(p)$ & $S E \beta$ \\
\hline Resource Scarcity & $.16(.07)$ & .09 \\
Socioeconomic Status & $-.25(.03)$ & .12 \\
Political Ideology & $.33(.01)$ & .13 \\
Socioeconomic Status $\times$ Resource Scarcity Interaction & $-.01(.92)$ & .12 \\
Political Ideology $\times$ Resource Scarcity Interaction & $-.11(.43)$ & .13 \\
Political Ideology $\times$ Socioeconomic Status Interaction & $.18(.17)$ & .13 \\
Socioeconomic Status $\times$ Resource Scarcity $\times$ Political Ideology Interaction & $-.11(.42)$ & .13 \\
$R^{2}$ & & .19 \\
\hline
\end{tabular}

\subsubsection{Additional analyses}

In anticipating potential alternative explanations for our findings, we considered whether scarcity of resources would lead individuals to indiscriminately lash out at others, rather than specifically shaping preferences for capital punishment. For example, previous research in social psychology suggests that feeling bad about oneself can lead individuals to denigrate others as a way of increasing self-esteem (e.g., Allen \& Sherman, 2011). Additional research suggests that feelings of stress and anxiety are associated with greater egocentrism and reduced perspective taking (e.g., Todd, Forstmann, Burgmer, Brooks, \& Galinsky, 2015). If so, greater endorsement of the death penalty under conditions of resource scarcity might simply reflect a general elevation in callousness or disregard for others. ${ }^{2}$ Three items from the Moral Foundations Questionnaire (Graham, Haidt, \& Nosek, 2008), initially included in our study for exploratory purposes outside the scope of the present hypotheses, enabled us to investigate whether our scarcity manipulation led to increased callousness. The questionnaire prompts participants to report the extent to which they consider certain factors when deciding something is right or wrong. Participants report the importance of each factor on a 6-point scale ranging from 0 (strongly disagree) to 5 (strongly agree). The three considerations relevant for assessing callousness are as follows: "whether or not someone cared for someone weak or vulnerable," "whether or not someone suffered emotionally," and "whether or not someone was cruel." These items were selected for their face-validity as indicators of one's disregard for the plight of others.

We separately regressed responses to each of the callousness items onto the dummycoded resource availability condition and found that the resource manipulation did not affect participants' responses to any of these items (all $p s>.35$ ). This suggests that activating scarcity concerns led to increased endorsement of the death penalty, specifically, rather than a general increase in cold-heartedness.

\subsection{Conclusions}

Our predictions received marginally significant support, with participants in the resource scarcity condition preferring the death penalty as compared to participants in the resource abundance condition. As expected, these effects were relatively small. Death penalty attitudes tend to be long-held, principled, and strong (Ellsworth \& Ross, 1983). Therefore, they 
are robust against minor laboratory interventions. By including individuals who were adamantly opposed to the death penalty in our sample, we made it even more difficult to detect our effects. Yet, despite being small in size, an effect of scarcity on endorsement of the death penalty emerged and did not appear to reflect a mere increase in general callousness.

Our findings also persisted after controlling for participants' political ideology, were not explained solely by differences in participant SES, and participant SES did not moderate the effect of resource condition on endorsement of the death penalty. Although at first glance this might appear surprising, it coheres with previous research examining scarcity's effects on behavior. For example, both White and colleagues (2013a) and Hill et al. (2012) fail to find moderating effects of SES when exploring scarcity's effects on attitudes toward redistribution and consumer spending, respectively. Here we have argued that, regardless of one's objective economic standing, activating concerns about resource scarcity leads individuals to consider their potential losses; thus, scarcity should threaten both high- and low-SES individuals. We continue to explore the potential effects of participant SES in Study 4, with the inclusion of a more robust measure of SES.

Study 3 provides initial, albeit tenuous, support for a causal relationship between resource scarcity and increased favorability toward the death penalty. We propose that this relationship may reflect the workings of a functional error management system (Haselton \& Nettle, 2006; Nesse, 2005). Survival is more precarious when resources are scarce than when resources are abundant; thus, given the energetic costs (and possible failure) of rehabilitation, the risks and costs associated with giving "second chances" to serious offenders are likely to be relatively high. We therefore predicted that error management might lead individuals to increase endorsement of capital punishment during times of perceived scarcity by increasing the perceived risks of keeping convicted murderers alive. Study 4 aimed to test this putative mediating mechanism, in addition to serving as a replication of the causal link between perceived resource scarcity and increased endorsement of the death penalty suggested by Study 3 .

\section{Study 4}

In Study 3, we found initial experimental evidence that perceived resource scarcity leads individuals to increase their favorability toward the death penalty. In Study 4 , we test our proposed mediator, predicting that resource scarcity increases the perceived risks of keeping severe transgressors in the group, thereby increasing favorability toward eliminationfocused punishments (such as the death penalty).

Although there is surface similarity between beliefs about the risks of keeping convicted criminals alive and general endorsement of the death penalty, these variables are conceptually distinct. Our measure of death penalty endorsement assesses how one feels toward the death penalty, generally speaking (i.e., Is it good or bad? Should we have more of it or less of it?). In contrast, the cost of error measure assesses why the death penalty should be employed. There are numerous reasons why an individual might favor the death penalty - for example, a desire for revenge, belief in its deterrent effect, belief in its cost effectiveness, or a general belief that murderers deserve to die (O'Neil et al., 2004). The cost of 
error measure captures one specific calculus for why the death penalty should be employed - a product of weighing the risks associated with keeping severe transgressors alive. Our mediation analysis thus aims to test whether resource scarcity leads individuals to recalibrate the risks of keeping convicted murderers alive, thereby shifting how positively they feel toward the death penalty.

In addition, Study 4 examines whether these effects are limited to individuals for whom the death penalty is a viable punishment option under at least some circumstances ("death qualified" individuals). In the United States, "death qualification" is an exclusion criterion authorized by the Supreme Court in Witherspoon v. Illinois (1968; see also Lockhart v. McCree, 1986). It is used in capital cases to prohibit individuals who are extremely attitudinally committed to their view of the death penalty (either as a staunch abolitionist or as a staunch supporter for every guilty defendant no matter the circumstances) from serving as jurors. From the law's perspective, staunch abolitionists will never vote to execute, and staunch supporters will always vote to execute. Thus, these jurors are pre-committed to a position and assumed to be unresponsive to information presented during the penalty phase of a capital case. Given that the law requires jurors to listen and use such information in reaching their judgments, both staunch abolitionists and staunch supporters are excluded from service, because they are, effectively, unable to follow the law.

Including this same criterion in our study serves two valuable purposes. First, it increases the ecological validity of the findings by limiting the sample to individuals whose attitude toward the death penalty would permit them to serve as jurors in capital cases in the United States. Second, it establishes a cogent boundary condition for our findings. We do not suggest that a mere laboratory prime activating concerns of resource availability is sufficient to alter strongly held convictions about the appropriateness of the death penalty. Although the psychological mechanisms under study are the same for death qualified and non-death-qualified participants, the law does not believe abolitionist jurors will budge from their predetermined position; we extend this logic to participants in the lab. Thus, our prediction is that, with respect to individuals for whom the death penalty is a conceivable punishment option, perceived resource scarcity will lead these individuals to increase their favorability toward the death penalty.

\subsection{Materials and methods}

\subsubsection{Participants}

Two hundred four participants (70 female, $M_{\text {age }}=33.98$ years) were recruited in 2014 through Amazon's Mechanical Turk in exchange for $\$ 0.50$ compensation. This sample size was determined in consideration of our Study 3 effect sizes and to ensure a sufficient number of death qualified participants.

\subsubsection{Procedure}

Participants were told they would take part in a study examining individuals' perceptions of different environments and provided their informed consent before beginning the experiment. Participants were then instructed to carefully examine a series of photographs 
and accompanying text, and to imagine themselves in the environments presented. Participants were then randomly assigned to view one of the two conditions employed in Study 3 , indicating either that the economy is currently suffering or prosperous. After viewing the photos and text, participants were asked to respond to questions about their attitudes regarding the criminal justice system. These measures included questions assessing participants' calculation of risks (our putative mediating mechanism), general endorsement of the death penalty, and a death qualification item. Participants then completed the demographic measures described in Study 3, including a revised measure of socioeconomic status. Finally, participants were fully debriefed and thanked for their time.

\subsubsection{Cost of error measure}

We predicted that resource scarcity increases endorsement of the death penalty by shifting participants' perceived cost of error in favor of executing convicted murderers. This mental calculation of risks associated with keeping transgressors in the group was measured with five Likert-type items ranging from 1 (strongly disagree) to 7 (strongly agree). Items included "Keeping convicted murderers alive is too great a risk for society to take," "It is better to execute convicted murderers than risk they will murder again," and "The death penalty is the only way to ensure a convicted murderer does not murder again." Responses to these items were aggregated to form a scale composite score $(\alpha=0.92)$.

\subsubsection{Death penalty attitudes measure}

Participants responded to six items assessing their general endorsement of the death penalty, including items utilized in Study 3 (e.g., "The death penalty should be used more often than it is"). The number of items was increased with the aim of developing a more sensitive, finely tuned measure of favorability toward the death penalty. Responses were reported on a 7-point scale ranging from 1 (strongly disagree) to 7 (strongly agree) and were aggregated to form a scale composite score $(\alpha=0.96)$. As expected, the death penalty endorsement measure was significantly correlated with the cost of error measure, $r=.84, p<.001$.

\subsubsection{Death qualification measure}

We approximated the judicial exclusion process in our study with the following item: "Do you feel so strongly about the death penalty (either for or against it) that it would prevent or substantially impair the performance of your duty as a juror in a capital case?" Individuals were asked to respond either "yes" or "no" to this item. The language of the death qualification item mirrors that used by judges when evaluating potential jurors for capital cases. Participants who responded "yes" to this item $(n=80)$ were excluded from our main analyses, though we report findings from both groups below.

Prior to conducting our focal analyses, we examined whether participants' responses to the death qualification screening item were influenced by the resource availability manipulation and found that they were not, $\chi^{2}(1, N=204)=.12, p>.25$.

\subsubsection{Participant socioeconomic status}

To better evaluate the potential effect of participants' SES on attitudes toward the death penalty, we included the same single-item measure as Study 3 and a 4-item self-report 
measure of subjective socioeconomic status (e.g., Griskevicius et al., 2011). Items from the latter measure were reported on a 7-point scale ranging from Strongly Disagree to Strongly Agree, and included, "I currently have enough money to buy things I want" and "I don't currently need to worry too much about paying my bills." Responses were aggregated to form a scale composite score $(\alpha=.91)$.

\subsection{Results}

\subsubsection{Death qualified participants}

We hypothesized that resource scarcity increases endorsement of the death penalty by shifting individuals' perceptions of the risks associated with keeping severe transgressors in the group. Study 4 tested these predictions by manipulating information regarding resource availability, measuring people's perceived cost of error and endorsement of the death penalty, and testing whether threat-induced differences in cost of error statistically mediates the relationship between resource availability and attitudes toward the death penalty. Here, we present findings for the death-qualified and non-death-qualified participants separately. Results from the combined sample mirror those for the death qualified participants - albeit with smaller effects - and are presented in the Supplement.

Replicating our main finding from Study 3, "death qualified" participants exposed to the resource scarcity manipulation reported greater endorsement of the death penalty $\left(M_{\text {predicted }}=4.89, S E_{\text {predicted }}=.25\right)$ than participants exposed to the resource abundance manipulation $\left(M_{\text {predicted }}=4.25, S E_{\text {predicted }}=.18\right)(\beta=.23, p=.01)$. As in Study 3, we regressed participants' reported endorsement of the death penalty onto socioeconomic status, political ideology, and resource condition as well as all interaction terms in a single regression model. As before, the effect of resource availability held controlling for participant socioeconomic status and political ideology. Although participants' political conservatism was once again a significant predictor of endorsement of the death penalty $(\beta=.44, p=.001)$, the effect of resource scarcity on death penalty endorsement persisted $(\beta=.20, p=.02)$. Here, unlike in Study 3, participants' socioeconomic status was not a significant predictor of death penalty endorsement using the composite measure $(p=.54)$ or single-item measure $(p=.47)$. None of the interaction terms were significant using either measure (all $p s>.17)$. See Table 6 (reporting findings using the composite SES measure).

Table 6. Study 4. Summary of Regression Analysis for Variables Predicting Death Qualified Participants' Endorsement of the Death Penalty $(\mathrm{N}=120)$

\begin{tabular}{lcc}
\hline Variable & $\beta(p)$ & $S E \beta$ \\
\hline Resource Scarcity & $.20(.02)$ & .08 \\
Socioeconomic Status & $-.07(.54)$ & .12 \\
Political Ideology & $.44(.001)$ & .12 \\
Socioeconomic Status $\times$ Resource Scarcity Interaction & $.16(.17)$ & .12 \\
Political Ideology $\times$ Resource Scarcity Interaction & $-.15(.23)$ & .12 \\
Socioeconomic Status $\times$ Political Ideology Interaction & $-.12(.32)$ & .12 \\
Socioeconomic Status $\times$ Resource Scarcity $\times$ Political Ideology Interaction & $.02(.83)$ & .11 \\
$R^{2}$ & & .21 \\
\hline
\end{tabular}


In a similar regression model, we then examined whether resource scarcity shifted participants' perceived cost of error in favor of executing convicted murderers. As predicted, participants primed with resource scarcity reported greater willingness to err on the side of executing convicted murderers $\left(M_{\text {predicted }}=4.44, S E_{\text {predicted }}=.23\right)$ than participants primed with resource abundance $\left(M\right.$ predicted $\left.=3.67, S E_{\text {predicted }}=.17\right)(\beta=.29, p=.001)$. Including participant socioeconomic status and political ideology as covariates did not significantly alter this result. Participants' socioeconomic status was not a significant predictor of participants' cost of error in favor of execution (composite measure: $p=.13$; single-item measure: $p=.61$ ). Although participants' political conservatism was a significant predictor of participants' cost of error in favor of execution $(\beta=.32, p=.01)$, the effect of resource scarcity still accounted for a significant proportion of variance in perceived cost of error $(\beta=.27, p=.003)$. Moreover, this effect was not moderated by socioeconomic status, political ideology, or the interaction of the two (all $p$ s $>$.24). See Table 7 .

Table 7. Study 4. Summary of Regression Analysis for Variables Predicting Death Qualified Participants' Perceived Cost of Error $(\mathrm{N}=121)$

\begin{tabular}{lcc}
\hline Variable & $\beta(p)$ & $S E \beta$ \\
\hline Resource Scarcity & $.27(.003)$ & .09 \\
Socioeconomic Status & $-.18(.13)$ & .12 \\
Political Ideology & $.32(.01)$ & .13 \\
Socioeconomic Status $\times$ Resource Scarcity Interaction & $.14(.24)$ & .12 \\
Political Ideology $\times$ Resource Scarcity Interaction & $-.07(.56)$ & .12 \\
Socioeconomic Status $\times$ Political Ideology Interaction & $-.07(.57)$ & .12 \\
Socioeconomic Status $\times$ Resource Scarcity $\times$ Political Ideology Interaction & $-.05(.65)$ & .12 \\
$R^{2}$ & & .18 \\
\hline
\end{tabular}

To examine whether differences in perceived cost of error statistically mediated shifts in endorsement of the death penalty, we used Preacher and Hayes' (2008) bootstrapping method to test for a significant indirect effect of resource scarcity on endorsement of the death penalty for 5,000 bootstrapped samples. The indirect effect of resource scarcity on endorsement of the death penalty was estimated to lie between 0.225 and 0.956 with $95 \%$ confidence $(\beta=0.588, S E=0.185)$. Because zero was not included in the $95 \%$ confidence intervals, this analysis demonstrates significant statistical mediation. The scarcity threat prime altered participants' cost of error, which in turn predicted participants' endorsement of the death penalty. The direct effect of scarcity on endorsement of the death penalty becomes statistically nonsignificant when cost of error is included in the equation $(p=.61)$, suggesting full mediation (Fig. 1). 


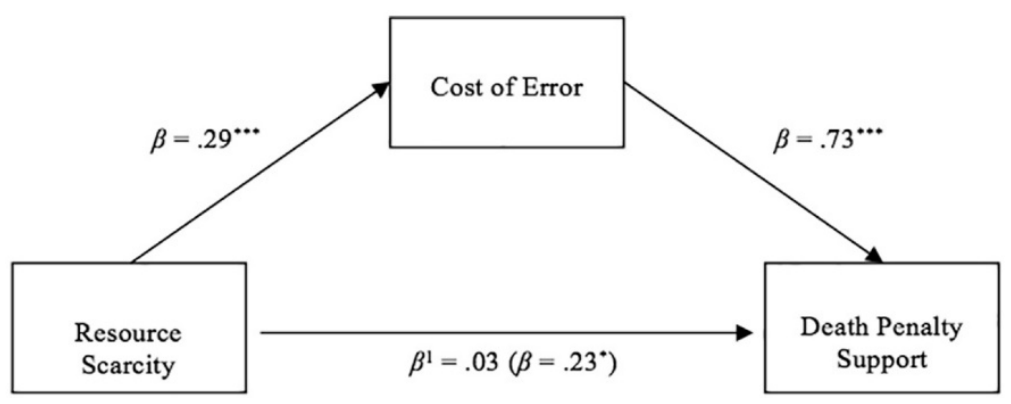

Figure 1. Standardized regression coefficients and $p$-values for the relationship between resource scarcity and endorsement of the death penalty as mediated by cost of error (Study 4).

\subsubsection{Non-death-qualified participants}

We would not expect to find a significant effect of resource scarcity or cost of error within participants who are not "death qualified"; our hypotheses were specific to individuals for whom the death penalty could be considered, under at least some circumstances, an acceptable punishment strategy. Indeed, non-death-qualified participants primed with resource scarcity did not exhibit increased favorability toward the death penalty as compared to those primed with resource abundance $(\beta=0.05, p=.70)$, and non-death-qualified participants primed with resource scarcity did not differ from participants primed with resource abundance in reported willingness to err on the side of executing convicted murderers $(\beta=0.01, p=.93)$. Thus, individuals who are staunchly confirmed in their beliefs (either for or against the death penalty) do not increase their favorability toward capital punishment in response to our resource scarcity prime. Given how strongly held these beliefs tend to be, it is unsurprising that our effects are specific to only those individuals whose openness to the death penalty would qualify them to serve as jurors on a capital case in the United States.

\subsection{Conclusions}

Study 4, using a "death qualified" sample, replicated Study 3 and further supported our hypotheses. During periods of perceived resource scarcity, concerns about the continuing risk that serious offenders pose to the group increases individuals' endorsement of eliminationfocused punishment. Consistent with Study 3, this effect occurs above and beyond participants' socioeconomic status and self-reported political ideology. Moreover, our findings in Study 4 demonstrate that the relationship between resource scarcity and endorsement of the death penalty is statistically mediated by shifts in the perceived risks associated with keeping convicted murderers alive.

\section{Discussion}

In a series of four studies, we find converging evidence supporting our hypothesis that perceived resource scarcity increases endorsement of the death penalty. Using archival measures of resource availability and death penalty statistics, we find that indicators of 
resource scarcity predict codification of capital punishment at the nation level and within the United States (Studies 1 \& 2). Moreover, experimentally manipulating perceived resource availability shifts death penalty beliefs; when resources are scarce, endorsement of capital punishment increases (Studies 3 \& 4). Additionally, we demonstrate that resource scarcity shifts risk calculations in favor of executing severe offenders, which increases endorsement of capital punishment (Study 4).

\subsection{Implications}

These findings support a functional psychology of punishment. Although proximate explanations of beliefs about capital punishment (e.g., political ideology, religiosity) are informative, an evolutionary approach provides additional insight into economically "irrational" punishment preferences. For example, in the United States, maintaining the death penalty is an expensive endeavor - costing an estimated additional \$184 million per year in California alone, compared to a "life without parole" permanent imprisonment system (Alarcon \& Mitchell, 2012). Yet, the evolved mind may not be naturally attuned to these modern administrative processes, relying instead on the kinds of cues (e.g., resource availability) that would have usefully informed punishment strategies across our evolutionary history. What appears economically irrational likely remains deeply rational (Ariely, 2008; Kahneman, 2011; Kenrick, Li, White, \& Neuberg, 2012).

Our findings may also help explain the recent trend toward abolition occurring within highly developed, resource-abundant countries. Indeed, we demonstrate that economically developed countries are less likely to retain the death penalty. The same finding emerged within-nation as well: in the United States, wealthier states are less likely to retain the death penalty than poorer states. Despite being an objectively wealthy country (in an international context), relatively poor (in a local, U.S. context) states endorse capital punishment.

\subsection{Future directions}

The present studies investigated whether an unexplored ecological factor, resource availability, can influence the cost-benefit calculus engaged when determining whether to permanently remove serious transgressors from the group. However, a potentially important moderator - the future expected value of that offender's contributions to the group-remains to be explored. As previous research illustrates, the future "association value" of an offender influences whether we employ punitive or rehabilitative strategies toward those specific individuals (Petersen, Sell, Tooby, \& Cosmides, 2012). Such findings suggest that when an offender possesses certain expertise or social capital, the cost of rehabilitating that individual might remain lower than the cost of expulsion regardless of resource availability. Indeed, depending on the expertise, removing skilled group members might be especially costly during times of scarcity (e.g., individuals with specialized knowledge related to hunting, gathering, or raiding). Future studies could directly address nuances within such cost-benefit analyses by directly manipulating the offender's value to the group, as well as perceived likelihood of successful rehabilitation. 


\subsection{Alternative explanations}

The current study presents an initial exploration of whether perceived resource scarcity functionally shapes individuals' attitudes toward the death penalty. Our hypotheses were derived from evolutionary theory and fit within a broader literature supporting an evolved psychology that responds flexibly to cues of resource availability (e.g., Griskevicius et al., 2011; Hill et al., 2012; Neuberg \& Schaller, 2016; White et al., 2013a, b).

One could argue, post hoc, that the predictions tested in the current paper could be derived from alternative frameworks. As just one example, system justification theory might suggest that resource scarcity threatens the social status quo, which leads people to more strongly endorse features of the system (such as capital punishment) as a means of reducing uncertainty and conflict (Jost, Banaji, \& Nosek, 2004). ${ }^{3}$ Certainly, we do not claim that an evolutionary perspective is the only framework that could possibly generate our particular findings. First, however, we note that extant frameworks have not generated a priori predictions about the ways in which resource scarcity shapes death penalty attitudes, nor have they proffered a mediating psychological mechanism for these processes, as is described here. Second, our broader approach generates predictions difficult to explain from alternative perspectives - for example, that resource scarcity would lead individuals to increase their endorsement of the death penalty for low "association value" targets but not high "association value" targets (Petersen, Sell, Tooby, \& Cosmides, 2012). Third, and more generally, it is useful to remember that explanations at different levels of analysis should rarely be assumed, a priori, to constitute alternatives. More likely, proximate explanations characterize mechanisms through which more ultimate causes have their effects, as when ecological features engage psychological mechanisms that create social preferences (e.g., Sng, Neuberg, Varnum, \& Kenrick, 2018). Ultimately, we believe this line of research offers rich opportunities to reconcile proximate and ultimate explanations of death penalty attitudes, providing a more textured understanding of the psychology of punishment.

\subsection{Conclusions}

Our findings suggest that even seemingly insignificant factors such as perceived fluctuations in resource availability may influence individuals' endorsement of the death penalty. Although the effect of environmental scarcity may be relatively small, this effect could have profound implications for public policy (Prentice \& Miller, 1992). Public views of capital punishment could influence upcoming elections as well as legislative attempts to abolish capital punishment. Future research could expand these findings by testing their implications for decision-making in political and legislative settings. Additionally, knowledge of how these factors influence people's attitudes toward capital punishment may illuminate variability in the sentencing of individual offenders. Understanding what peripheral factors influence juror decision-making becomes especially important when the consequences are-quite literally-life or death. 


\section{Notes}

1. For exploratory purposes, we examined whether participant sex influenced reported endorsement of the death penalty. We found no effect of sex on endorsement of the death penalty $(p=$ .19), and sex did not interact with resource condition $(p=.55)$.

2. We thank Bill von Hippel for drawing our attention to this possibility.

3. We thank an anonymous reviewer for posing this alternative.

Acknowledgments - This research was financially supported by research funds provided to Steven L. Neuberg by the Arizona State University Foundation for a New American University. The authors have no competing interests to declare.

\section{References}

Alarcon, A. L., \& Mitchell, P. M. (2012). Costs of capital punishment in California: Will voters choose reform this November. Loyola of Los Angeles Law Review, 46, S1-S34.

Amnesty International, Death penalty, Retrieved from https:/www.amnesty.org/en/what-we-do/ death-penalty/, 2012.

Allen, T. J., \& Sherman, J. W. (2011). Ego threat and intergroup bias: A test of motivated-activation versus self-regulatory accounts. Psychological Science, 22, 331-333.

Amnesty International (2017). Death penalty. Retrieved from https:/www.amnesty.org/en/whatwe-do/death-penalty/.

Ariely, D. (2008). Predictably irrational. New York: HarperCollins.

Boehm, C. (2012). Costs and benefits in hunter-gatherer punishment. Behavioral and Brain Sciences, 35, 19-20.

Boyd, R., \& Richerson, P. J. (2006). Culture and the evolution of the human social instincts. Roots of Human Sociality, 453-477.

Chakravarthy, M. V., \& Booth, F. W. (2004). Eating, exercise, and "thrifty" genotypes: Connecting the dots toward an evolutionary understanding of modern chronic diseases. Journal of Applied Physiology, 96, 3-10.

CIA World Factbook (2012). The World Factbook: Population. Retrieved from https://www.cia.gov/ library/publications/the-world-factbook/geos/xx.html.

CIA World Factbook (2017). The World Factbook: Distribution of Family Income-GINI Index. Retrieved from https:/www.cia.gov/library/publications/the-world-factbook/rankorder/2172rank.html.

Daly, M. (2016). Killing the competition: Economic inequality and homicide. New Brunswick, NJ: Transaction.

Death Penalty Information Center. State by State Database. Retrieved from http://www.deathpenaltyinfo .org/state-info-link, 2012.

Death Penalty Information Center (2012). State by state database. Retrieved from http://www.death penaltyinfo.org/state-info-link.

Ellsworth, P. C., \& Ross, L. (1983). Public opinion and capital punishment: A close examination of the views of abolitionists and retentionists. Crime $\mathcal{E}$ Delinquency, 29, 116-169.

Gallup State Ideology Survey (2012). State of the states. Retrieved from http://news.gallup.com/poll/ 125066/state-states.aspx.

Gelfand, M. J., Raver, J. L., Nishii, L., Leslie, L. M., Lun, J., Lim, B. C., . . Aycan, Z. (2011). Differences between tight and loose cultures: A 33-nation study. Science, 332, 1100-1104. 
Graham, J., Haidt, J., \& Nosek, B. A. (2008). The moral foundations questionnaire. Retrieved from moralfoundations.org.

Griskevicius, V., Ackerman, J. M., Cantu, S. M., Delton, A. W., Robertson, T. E., Simpson, J. A., . . Tybur, J. M. (2013). When the economy falters, do people spend or save? Responses to resource scarcity depend on childhood environments. Psychological Science, 24, 197-205.

Griskevicius, V., Delton, A. W., Robertson, T. E., \& Tybur, J. M. (2011). Environmental contingency in life history strategies: The influence of mortality and socioeconomic status on reproductive timing. Journal of Personality and Social Psychology, 100, 241-254.

Haselton, M. G., \& Nettle, D. (2006). The paranoid optimist: An integrative evolutionary model of cognitive biases. Personality and Social Psychology Review, 10, 47-66.

Hill, S. E., Rodeheffer, C. D., Durante, K., Griskevicius, V., \& White, A. E. (2012). Boosting beauty in an economic decline: Mating, spending, and the lipstick effect. Journal of Personality and Social Psychology, 103, 275-291.

Inequality-adjusted Human Development Index (2011). Retrieved from http://hdr.undp.org/en/content/ inequality-adjusted-human-development-index-ihdi.

Jost, J. T., Banaji, M. R., \& Nosek, B. A. (2004). A decade of system justification theory: Accumulated evidence of conscious and unconscious bolstering of the status quo. Political Psychology, 25, 881-919.

Kahneman, D. (2011). Thinking, fast and slow. New York, NY: Farrar, Straus and Giroux.

Kenrick, D. T., Li, Y. J., White, A. E., \& Neuberg, S. L. (2012). Economic subselves: Fundamental motives and deep rationality. Social Thinking and Interpersonal Behavior, 14, $23-43$.

Laran, J., \& Salerno, A. (2013). Life-history strategy, food choice, and caloric consumption. Psychological Science, 24, 167-173.

Lee, A. J., \& Zietsch, B. P. (2011). Experimental evidence that women's mate preferences are directly influenced by cues of pathogen prevalence and resource scarcity. Biological Letters, 7, 892-895.

Liang, B., Lu, H., Miethe, T. D., \& Zhang, L. (2005). Sources of variation in pro-death penalty attitudes in China: An exploratory study of Chinese students at home and abroad. British Journal of Criminology, 46(1), 119-130.

Lockhart v. McCree, 476 U.S. 162 (1986).

Measure of America (2014). The Measure of America 2013-2014. Retrieved from http://www.measureof america.org/wp-content/uploads/2013/06/MOA-III.pdf.

Miethe, T. D., Lu, H., \& Deibert, G. R. (2005). Cross-national variability in capital punishment: Exploring the sociopolitical sources of its differential legal status. International Criminal Justice Review, 15, 115-130.

Neapolitan, J. L. (2001). An examination cross-national variation in punitiveness. International Journal of Offender Therapy and Comparative Criminology, 45, 691-710.

Nesse, R. M. (2005). Natural selection and the regulation of defenses: A signal detection analysis of the smoke detector principle. Evolution and Human Behavior, 26, 88-105.

Neuberg, S. L., \& Cottrell, C. A. (2008). Managing the threats and opportunities afforded by human sociality. Group Dynamics: Theory, Research, and Practice, 12, 63-72.

Neuberg, S. L., \& Schaller, M. (2016). An evolutionary threat-management approach to prejudices. Current Opinion in Psychology, 7, 1-5.

Nolan, J. J. (2004). Establishing the statistical relationship between population size and UCR crime rate: Its impact and implications. Journal of Criminal Justice, 32, 547-555.

O'Neil, K. M., Patry, M. W., \& Penrod, S. D. (2004). Exploring the effects of attitudes toward the death penalty on capital sentencing verdicts. Psychology, Public Policy, and Law, 10, 443-470. 
Oreopoulos, P., \& Petronijevic, U. (2013). Making college worth it: A review of the returns to higher education. The Future of Children, 23, 41-65.

Otterbein, K. F. (1986). The ultimate coercive sanction: A cross-cultural study of capital punishment. HRAF Press.

Petersen, M. B., Sell, A., Tooby, J., \& Cosmides, L. (2012). To punish or repair? Evolutionary psychology and lay intuitions about modern criminal justice. Evolution and Human Behavior, 33, 682-695.

Preacher, K. J., \& Hayes, A. F. (2008). Asymptotic and resampling strategies for assessing and comparing indirect effects in multiple mediator models. Behavior Research Methods, 40, 879-891.

Prentice, D. A., \& Miller, D. T. (1992). When small effects are impressive. Psychological Bulletin, 112, 160-164.

Rodeheffer, C. D., Hill, S. E., \& Lord, C. G. (2012). Does this recession make me look black? The effect of resource scarcity on the categorization of biracial faces. Psychological Science, 23, 1476-1478.

Sarat, A. (2001). When the State Kills. Princeton, NJ: Princeton University Press.

Sharma, E., Mazar, N., Alter, A. L., \& Ariely, D. (2014). Financial deprivation selectively shifts moral standards and compromises moral decisions. Organizational Behavior and Human Decision Processes, 123, 90-100.

Sng, O., Neuberg, S. L., Varnum, M. E., \& Kenrick, D. T. (2018). The behavioral ecology of cultural psychological variation. Psychological Review. https://doi.org/10.1037/ rev0000104 in press.

Soss, J., Langbein, L., \& Metelko, A. R. (2003). Why do white Americans support the death penalty? The Journal of Politics, 65, 397-421.

Stringhini, S., Carmeli, C., Jokela, M., Avendaño, M., Muennig, P., Guida, F., \& Chadeau-Hyam, M. (2017). Socioeconomic status and the $25 \times 25$ risk factors as determinants of premature mortality: A multicohort study and meta-analysis of 1.7 million men and women. The Lancet, 389, 1229-1237.

Todd, A. R., Forstmann, M., Burgmer, P., Brooks, A. W., \& Galinsky, A. D. (2015). Anxious and egocentric: How specific emotions influence perspective taking. Journal of Experimental Psychology: General, 144, 374-391.

U.S. Census Bureau (2012). Population. Retrieved from https://www.census.gov/topics/population.html. U.S. Department of Commerce (2011). Bureau of economic analysis. Retrieved from www.bea.gov.

White, A. E., Kenrick, D. T., Neel, R., \& Neuberg, S. L. (2013). From the bedroom to the budget deficit: Mate competition changes men's attitudes toward economic redistribution. Journal of Personality and Social Psychology, 105, 924-940.

White, A. E., Li, Y. J., Griskevicius, V., Neuberg, S. L., \& Kenrick, D. T. (2013). Putting all your eggs in one basket: Life history strategies, bet hedging, and diversification. Psychological Science, 24, 715-722.

Witherspoon v. Illinois, 391 U.S. 510 (1968). 
Supplemental Appendix A: Additional Analyses

\section{Study 4}

Full sample (combined death qualified and non-death-qualified participants)

The analyses in the paper present results separately for the death-qualified and non-deathqualified participants. Here, for comprehensiveness, we present analyses for the full sample of participants.

As with our focal analyses in the paper, we first attempted to replicate our initial finding that resource scarcity increases endorsement of the death penalty using the full sample of participants. Again, we find that participants primed with resource scarcity reported greater endorsement of the death penalty than participants primed with resource abundance $(\beta=.51, p=.05)$. We then ran a linear regression model including participant socioeconomic status and political ideology as covariates, including all interaction terms. Although participants' political conservatism was a significant predictor of endorsement of the death penalty $(\beta=.31, p=.001)$, resource scarcity remained a marginally significant predictor of death penalty endorsement $(\beta=.12, p=.09)$. Participants' socioeconomic status was not a significant predictor of death penalty endorsement (composite measure: $p=.49$; single-item measure: $p=.07$ ). The effect of resource scarcity on death penalty endorsement was not moderated by socioeconomic status, political ideology, or the interaction of the two (all $p \mathrm{~s}>.25$ ). See Supplemental Table 1.

We then examined whether resource scarcity shifted participants' perceived cost of error in favor of executing convicted murderers. As predicted, participants primed with resource scarcity reported greater willingness to err on the side of executing convicted murderers than participants primed with resource abundance $(\beta=.16, p=.02)$. Again, we examined whether this effect held after controlling for participant socioeconomic status and political ideology by regressing 
participants' reported cost of error onto socioeconomic status, political ideology, resource condition, and all interaction terms. Participants' socioeconomic status was not a significant predictor of participants' cost of error in favor of execution (composite measure: $p=.86$; single-item measure: $p=.20$ ). Although participants' political conservatism was a significant predictor of participants' cost of error in favor of execution $(\beta=.28, p=.005)$, the effect of resource scarcity still accounted for a substantial proportion of variance in perceived cost of error $(\beta=.15, p=.03)$. Moreover, this effect was not moderated by socioeconomic status, political ideology, or the interaction of the two (all $p \mathrm{~s}>.23$ ). See Supplemental Table 2.

To examine whether changes in perceived cost of error mediated shifts in endorsement of the death penalty, we used Preacher and Hayes' (2008) bootstrapping method to test for a significant indirect effect of resource scarcity on endorsement of the death penalty for 5,000 bootstrapped samples. The indirect effect of resource scarcity on endorsement of the death penalty was estimated to lie between 0.678 and 0.927 with $95 \%$ confidence $(\beta=0.503, S E=0.22$ ). Because zero was not included in the $95 \%$ confidence intervals, this analysis demonstrates significant mediation. That is, the scarcity threat prime altered participants' cost of error, which, in turn, predicted participants' endorsement of the death penalty. The direct effect of scarcity on endorsement of the death penalty becomes statistically nonsignificant when cost of error is included in the equation $(p>.25)$, suggesting full mediation. See Supplemental Figure 1.

Finally, we conducted a 2 (Death Qualification: Yes, No) $\times 2$ (Resource Availability: Scarcity, Abundance) ANOVA with death penalty endorsement as our dependent variable. There was a significant main effect of death qualification, such that death qualified participants ( $M=4.57$, $S D=1.42)$ exhibited greater endorsement of the death penalty than non-death-qualified partici- 
pants $(M=2.92, S D=2.04), F(1,196)=45.49, p<.001$ partial eta $^{2}=.19$. There was a marginally significant main effect of resource condition, such that participants in the scarcity condition $(M=4.19, S D=1.79)$ exhibited greater endorsement of the death penalty than participants in the abundance condition $(M=3.67, S D=1.91), F(1,196)=2.85, p=.09$, partial eta ${ }^{2}=.01$. The Death Qualification $\times$ Resource Availability interaction was not significant, $p=.35$. We note that our non-death-qualified sample was significantly smaller $(n=78)$ than our death qualified sample $(n=122)$, increasing the difficulty of detecting a significant interaction.

In sum, our findings using the full sample of participants mirror our findings within the death qualified participants reported in Study 4, despite including participants who stated having such strong views opposing the death penalty that their ability to be impartial in making death penalty decisions would be impaired. 
Figure S1. Standardized regression coefficients and p-values for the relationship between resource scarcity and endorsement of the death penalty as mediated by cost of error in full sample of participants (Study 4).

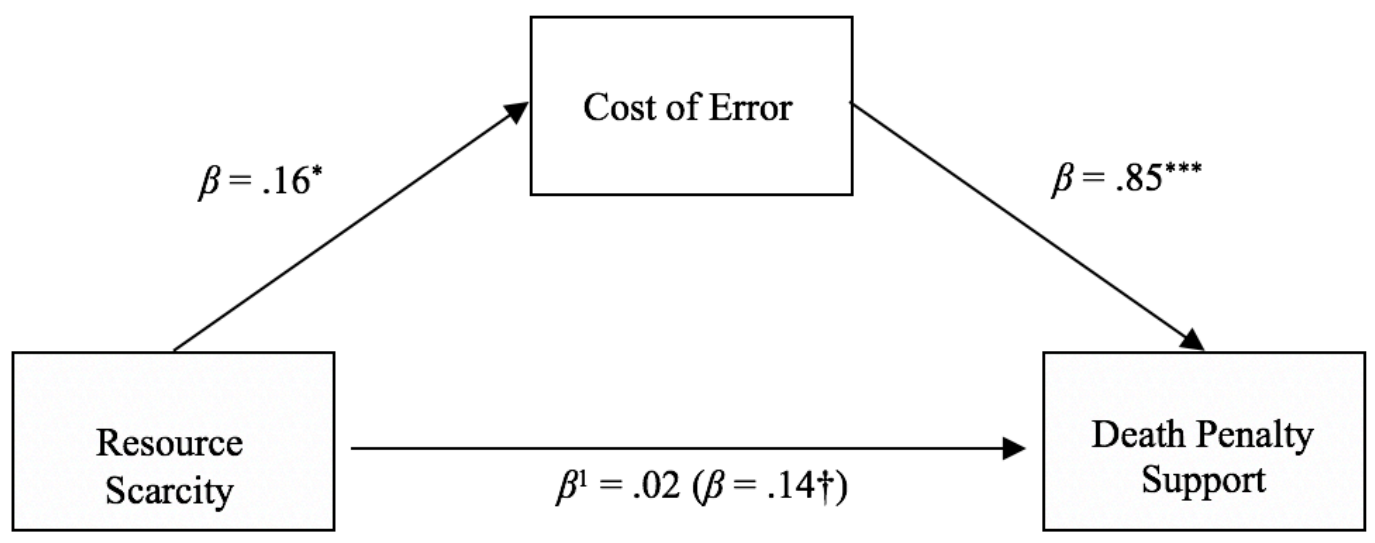

Note: $\uparrow p=.051,{ }^{*} p<.05,{ }^{* * *} p<.001$

Table S1. Summary of Regression Analysis for Variables Predicting Participants' Endorsement of the Death Penalty (full sample, $\mathrm{N}=198$ )

\begin{tabular}{lll}
\hline Variable & $\beta(\mathrm{p})$ & $\mathrm{SE} \beta$ \\
\hline Resource Scarcity & $.12(.09)$ & .07 \\
Socioeconomic Status & $.07(.49)$ & .10 \\
Political Ideology & $.31(.001)$ & .10 \\
Socioeconomic Status $\times$ Resource Scarcity Interaction & $-.02(.84)$ & .10 \\
Political Ideology $\times$ Resource Scarcity Interaction & $-.04(.68)$ & .09 \\
Socioeconomic Status $\times$ Political Ideology Interaction & $-.01(.88)$ & .09 \\
Socioeconomic Status $\times$ Resource Scarcity $\times$ Political & $.02(.85)$ & .09 \\
$\quad$ Ideology Interaction & & .11 \\
$\mathrm{R}^{2}$ & & \\
\hline
\end{tabular}


Table S2. Summary of Regression Analysis for Variables Predicting Death Qualified Participants' Perceived Cost of Error (full sample, $\mathrm{N}=199$ )

\begin{tabular}{lcc}
\hline Variable & $\beta(\mathrm{p})$ & $\mathrm{SE} \beta$ \\
\hline Resource Scarcity & $.15(.03)$ & .07 \\
Socioeconomic Status & $-.02(.86)$ & .10 \\
Political Ideology & $.28(.005)$ & .10 \\
Socioeconomic Status $\times$ Resource Scarcity Interaction & $.01(.89)$ & .10 \\
Political Ideology $\times$ Resource Scarcity Interaction & $-.05(.64)$ & .10 \\
Socioeconomic Status $\times$ Political Ideology Interaction & $-.04(.66)$ & .09 \\
Socioeconomic Status $\times$ Resource Scarcity $\times$ Political & $.03(.78)$ & .09 \\
$\quad$ Ideology Interaction & & .09 \\
$\mathrm{R}^{2}$ & & \\
\hline
\end{tabular}


Supplemental Appendix C: Study Materials

\section{Study 3}

Participants were asked to rate items on how much they agreed with them from 1 (strongly disagree) to 9 (strongly agree).

Death Penalty Endorsement Scale:

I think the death penalty is necessary.

The death penalty should be used more often than it is.

The length of time between sentencing someone to death and actually executing them should be shorter than it currently is.

\section{Study 4}

Unless otherwise noted, participants were asked to rate items on how much they agreed with them from 1 (strongly disagree) to 7 (strongly agree).

Death Penalty Endorsement Scale:

I think the death penalty is necessary.

The death penalty should be used more often than it is.

It is immoral for society to take a life regardless of the crime the individual has committed. (R) For some crimes the death penalty is the most appropriate punishment regardless of how much money it costs to carry out an execution.

It is the moral responsibility of society to execute people who commit certain kinds of crimes. To what extent do you support the death penalty? (measured on a scale from 1 (not at all) to 7 (extremely))

Cost of Error Scale:

Keeping convicted murderers alive is too great a risk for society to take.

It is better to execute convicted murderers than risk they will murder again.

The death penalty is the only way to ensure a convicted murderer does not murder again.

Allowing a convicted murderer to eventually be released from prison greatly endangers society. It is so important to keep the rest of society safe that the legal system should err in the direction of executing murderers even if doing so might occasionally be an error. 